\title{
EDITORIAL
}

Vol. 42 (5): 868-871, September - October, 2016

doi: 10.1590/S1677-5538.IBJU.2016.05.02

\section{The case for excision and primary anastomotic urethroplasty for bulbar urethral stricture}

\author{
Jordan A. Siegel ${ }^{1}$, Allen F. Morey ${ }^{1}$ \\ ${ }^{1}$ Department of Urology, University of Texas Southwestern Medical Center, Dallas, TX, USA
}

With an estimated prevalence of 296 to 627 per 100.000 men, male urethral stricture disease imposes a significant burden on the health care system $(1,2)$. Urethroplasty has demonstrated durable, high success rates in the management of a wide spectrum of stricture disease, far exceeding that of the more commonly performed but less successful direct vision internal urethrotomy (DVIU) $(1,3-5)$. While procedure selection depends on stricture characteristics (length, location, and etiology), the high success rate of excision and primary anastomotic (EPA) urethroplasty makes it the procedure of choice for most strictures of the bulbar urethra (6). However, concerns regarding the effect of urethral transection on male sexual health has led some centers to advocate for substitution urethroplasty (7), likely contributing to an increase in these procedures (8). Our objective is to review the literature supporting EPA urethroplasty in strictures of the bulbar urethra.

\section{Success of EPA urethroplasty}

A 25-year meta-analysis of the contemporary EPA urethroplasty literature demonstrates a uniformly high level of success ( $>90 \%$ ) for EPA of bulbar strictures (6), superior to the results of any other method of bulbar urethroplasty $(9,10)$. In fact, a 4-fold increase in stricture recurrence has been reported in substitution urethroplasty when compared with EPA (11). While attempts to demonstrate equivalency between substitution urethroplasty and EPA have been reported, these studies suffer from patency rates that fall short of that ordinarily reported for EPA, as well as discrepant follow-up between treatment groups (12).

Unfortunately, DVIU remains the most frequently used treatment for anterior urethral stricture, despite its inferior results compared to urethroplasty $(1,3,13)$. This is often attributed to the simplicity and speed of endoscopic treatment and a lack of urologists trained in urethroplasty techniques, especially in various rural geographic locations $(2,14)$. At best, initial DVIU for short, non-traumatic strictures of the bulbar urethra has been associated with a success rate of only 39-73\%, with subsequent attempts performing even worse $(4,5,15)$. It is clear that after prior failed urethrotomy the complexity of the stricture increases (16). Current recommendations allow for a single attempt at DVIU in a well-selected patient before referring stricture patients for definitive urethroplasty $(17,18)$.

\section{UTSW EPA experience}

Our EPA technique emphasizes complete scar excision, while maintaining the vascular integrity of the spongiosum. Though EPA failure is rare, it is our belief that many failures are caused by inadequate proximal urethral dissection, leading to incomplete resection of diseased tissue. In order to opti- 
mize the proximal dissection, we utilize antegrade instrumentation via a suprapubic tract (if present), or retrograde placement of a guidewire, which aides in the identification of the proximal lumen. With control and adequate visualization of the proximal urethral stump, the strictured mucosa and associated spongiofibrosis is completely excised, leaving well-vascularized urethral tissue for a healthy anastomosis. We advocate performing a two-layer ventral anastomosis after urethral transection for precise re-approximation of the robust vasculature of the ventral spongiosum. We avoid additional maneuvers such as corporal splitting whenever possible, as they may further compromise antegrade and retrograde corporal blood flow to the urethra. Instead, we facilitate urethral lengthening by aggressively mobilizing the urethra from its ventral crotal attachments while preserving dorsal perforating vasculature as much as possible. Our results underscore the value of incorporating these various alternative technical measures to avoid urethral ischemia.

Adequate urethral length after transection is essential for a tension-free anastomotic repair. Despite traditional recommendations that the EPA technique be limited to strictures $2 \mathrm{~cm}$ or less long (21), our experience suggests that this underestimates the potential urethral length that can be mobilized via a perineal dissection (22). Male urethra has been shown to be exceptionally extensible, with a possible additional 65\% of length obtained after mobilization, allowing for a tension-free anastomosis even in longer strictures (23). It has been our experience that up to $5 \mathrm{~cm}$ resection is possible in the proximal bulb (lower half of perineal incision) in selected favorable cases, a $2 \mathrm{~cm}$ limit is more customary in the distal bulb (upper half of perineal incision).

\section{Complications of EPA urethroplasty}

Contemporary analysis of urethroplasty in the United States reveals a low post-operative complication rate of 6.6\% (8). Compared to anastomotic urethroplasty, substitution urethroplasty is associated with a 5 -fold increase in complications, though direct comparisons of the complication profiles are scant (11). It is clear however, that anastomotic repairs obviate the time and trauma needed for harvesting of flap or graft, thus avoiding those inherent complications $(24,25)$.

The complication of erectile dysfunction after anterior urethroplasty is a controversial topic with many divergent opinions (7). Overall, urethroplasty has been shown to cause transient post-operative erectile functional decline in up to $40 \%$ of patients (26). Multiple risk factors appear to be involved, such as patient age, stricture length and location, and type of reconstruction (26-28). While ED in anastomotic repairs has been shown to be significantly higher at three months post-operatively $(26,28,29)$, there is no demonstrable difference at 6 months and beyond $(26,28,30-35)$. In fact, overall sexual dysfunction after urethroplasty lasting beyond 6 months has been shown to be on par with circumcision (27).

\section{CONCLUSIONS}

Excision and primary anastomotic urethroplasty demonstrates the highest long-term success rate among available techniques for bulbar urethral strictures. The overall complications of EPA are low, and erectile dysfunction, if encountered, generally resolves after six months of recovery. EPA should be considered the gold standard in treatment of bulbar strictures.

\section{CONFLICT OF INTEREST}

None declared. 


\section{REFERENCES}

1. Santucci RA, Joyce GF, Wise M. Male urethral stricture disease. J Urol.2007;177:1667-74.

2. Figler BD, Gore JL, Holt SK, Voelzke BB, Wessells H. High regional variation in urethroplasty in the United States. J Urol.2015;193:179-83.

3. Anger JT, Buckley JC, Santucci RA, Elliott SP, Saigal CS; Urologic Diseases in America Project. Trends in stricture management among male Medicare beneficiaries: underuse of urethroplasty? Urology.2011;77:481-5.

4. Heyns CF, Steenkamp JW, De Kock ML, Whitaker P. Treatment of male urethral strictures: is repeated dilation or internal urethrotomy useful? J Urol.1998;160:356-8.

5. Naudé AM, Heyns CF. What is the place of internal urethrotomy in the treatment of urethral stricture disease? Nat Clin Pract Urol.2005;2:538-45.

6. Morey AF, Watkin N, Shenfeld 0, Eltahawy E, Giudice C. SIU/ ICUD Consultation on Urethral Strictures: Anterior urethra-primary anastomosis. Urology.2014;83:S23-6.

7. Palminteri E, Franco G, Berdondini E, Fusco F, De Cillis A, Gentile V. Anterior urethroplasty and effects on sexual life: which is the best technique? Minerva Urol Nefrol.2010;62:371-6.

8. Blaschko SD, Harris CR, Zaid UB, Gaither T, Chu C, Alwaal $A$, et al. Trends, utilization, and immediate perioperative complications of urethroplasty in the United States: data from the national inpatient sample 2000-2010. Urology.2015;85:1190-4.

9. Barbagli G, Kulkarni SB, Fossati N, Larcher A, Sansalone S, Guazzoni $G$, et al. Long-term followup and deterioration rate of anterior substitution urethroplasty. J Urol.2014;192:80813.

10. Chapple C, Andrich D, Atala A, Barbagli G, Cavalcanti A, Kulkarni S, etal. SIU/ICUD Consultation on Urethral Strictures: The management of anterior urethral stricture disease using substitution urethroplasty. Urology.2014;83:S31-47.

11. Andrich DE, Dunglison N, Greenwell TJ, Mundy AR. The long-term results of urethroplasty. J Urol.2003;170:90-2.

12. Chen ML, Odom BD, Santucci RA. Substitution urethroplasty is as successful as anastomotic urethroplasty for short bulbar strictures. Can J Urol.2014; 1:7565-9.

13. Ferguson GG, Bullock TL, Anderson RE, Blalock RE, Brandes SB. Minimally invasive methods for bulbar urethral strictures: a survey of members of the American Urological Association. Urology.2011;78:701-6.

14. Burks FN, Salmon SA, Smith AC, Santucci RA. Urethroplasty: a geographic disparity in care. J Urol.2012;187:2124-7.

15. Santucci R, Eisenberg L. Urethrotomy has a much lower success rate than previously reported. J Urol.2010;183:185962.

16. Hudak SJ, Atkinson TH, Morey AF. Repeat transurethral manipulation of bulbar urethral strictures is associated with increased stricture complexity and prolonged disease duration. J Urol.2012;187:1691-5.

17. Wessells H. Cost-effective approach to short bulbar urethral strictures supports single internal urethrotomy before urethroplasty. J Urol.2009;181:954-5.

18. Greenwell TJ, Castle C, Andrich DE, MacDonald JT, Nicol DL, Mundy AR. Repeat urethrotomy and dilation for the treatment of urethral stricture are neither clinically effective nor cost-effective. J Urol.2004;172:275-7.

19. Eltahawy EA, Virasoro R, Schlossberg SM, McCammon $\mathrm{KA}$, Jordan GH. Long-term followup for excision and primary anastomosis for anterior urethral strictures. J Urol.2007;177:1803-6.

20. Barbagli G, De Angelis M, Romano G, Lazzeri M. Long-term followup of bulbar end-to-end anastomosis: a retrospective analysis of 153 patients in a single center experience. J Urol.2007;178:2470-3.

21. Azoury BS, Freiha FS. Excision of urethral stricuture and end to end anastomosis. Urology.1976;8:138-40.

22. Morey AF, Kizer WS. Proximal bulbar urethroplasty via extended anastomotic approach--what are the limits? J Urol.2006;175:2145-9.

23. Da Silva EA, Sampaio FJ. Urethral extensibility applied to reconstructive surgery. J Urol.2002;167:2042-5.

24. Barbagli G, Fossati N, Sansalone S, Larcher A, Romano G, Dell'Acqua V, et al. Prediction of early and late complications after oral mucosal graft harvesting: multivariable analysis from a cohort of 553 consecutive patients. J Urol.2014;191:688-93.

25. McAninch JW, Morey AF. Penile circular fasciocutaneous skin flap in 1-stage reconstruction of complex anterior urethral strictures. J Urol.1998;159:1209-13.

26. Erickson BA, Granieri MA, Meeks JJ, Cashy JP, Gonzalez $\mathrm{CM}$. Prospective analysis of erectile dysfunction after anterior urethroplasty: incidence and recovery of function. J Urol.2010;183:657-61. 


\section{EDITORIAL}

27. Coursey JW, Morey AF, McAninch JW, Summerton DJ, Secrest C, White $P$, et al. Erectile function after anterior urethroplasty. J Urol.2001;166:2273-6.

28. Xie H, Xu YM, Xu XL, Sa YL, Wu DL, Zhang XC. Evaluation of erectile function after urethral reconstruction: a prospective study. Asian J Androl.2009;11:209-14.

29. Feng C, Xu YM, Barbagli G, Lazzeri M, Tang CY, Fu Q, et al. The relationship between erectile dysfunction and open urethroplasty: a systematic review and meta-analysis. J Sex Med.2013;10:2060-8.

30. Ekerhult T0, Lindqvist K, Peeker R, Grenabo L. Low risk of sexual dysfunction after transection and nontransection urethroplasty for bulbar urethral stricture. J Urol.2013;190:635-8.

31. El-Assmy A, Harraz AM, Benhassan M, Fouda M, Gaber $H$, Nabeeh $A$, et al. Erectile dysfunction post-perineal anastomotic urethroplasty for traumatic urethral injuries: analysis of incidence and possibility of recovery. Int Urol Nephrol.2015;47:797-802.

32. Dogra PN, Saini AK, Seth A. Erectile dysfunction after anterior urethroplasty: a prospective analysis of incidence and probability of recovery--single-center experience. Urology.2011;78:78-81.
33. Erickson BA, Wysock JS, McVary KT, Gonzalez CM. Erectile function, sexual drive, and ejaculatory function after reconstructive surgery for anterior urethral stricture disease. BJU Int.2007;99:607-11.

34. Anger JT, Sherman ND, Webster GD. The effect of bulbar urethroplasty on erectile function. J Urol.2007;178:1009-11.

35. Blaschko SD, Sanford MT, Cinman NM, McAninch JW, Breyer BN. De novo erectile dysfunction after anterior urethroplasty: a systematic review and meta-analysis. BJU Int.2013;112:655-63.

Allen F. Morey, MD

Department of Urology University of Texas Southwestern Medical Center Moss Bldg, $8^{\text {th }} \mathrm{Fl}$, Ste 112 5323 Harry Hines Blvd Dallas, TX, 75390-9110, USA

Fax: +1 214 648-8786 E-mail: allen.morey@utsouthwestern.edu 